\title{
Learning Analytics Lens: Improving Quality of Higher Education
}

\author{
Monika Hooda ${ }^{1}$, Chhavi Rana ${ }^{1}$ \\ ${ }^{1}$ Department of CSE, UIET, MDU, Rohtak, Haryana, 124001, India \\ monikahooda555@gmail.com, chhavi1jan@yahoo.com
}

\begin{abstract}
With digital revolution expansion and a rapid change in the technologies, educational data is increasing at a swift pace. Learning analytics (LA) turns out to be a powerful tool for improving learning and teaching practices. Learning analytics uncover hidden patterns, correlation, and other insights about learners and educators in educational big data that leads them to stay agile, better outcomes, and employability. This literature review aims to categorize such measures of data-driven improvement. A comprehensive review of Learning Analytics (LA) and Educational Data Mining (EDM) and significant techniques in higher education was conducted. Analysis of the research questions, methodology, techniques, learning environment, associated projects, and findings of various published papers is done and is accordingly categorized. Analysis of various reviews on the development and growth of LA in higher education in various countries is also done. The results provide a comprehensive background for understanding current knowledge on LA and EDM and its impact on both learner and instructor in the various learning environment. The results showed that in HEIs, where LA has been implemented aimed at better assessing and predicting learner's performance. It has also helped in monitoring and motivating them, discovering undesirable learning behaviors and their emotional states, help educators and administrators to unlock big data potentials, and making quicker datadriven decisions.
\end{abstract}

Key words: Collaborative learning, Games, Online learning, Pedagogical issues;

\section{INTRODUCTION}

The integration of digital and mobile technologies with the higher education sector affects both the learning and teaching environment. Learning analytics help Higher Educational Institutes (HEIs) in many aspects of learning and teaching by utilizing the data generated about students and their learning background. There is a close relation between Academic Analytics, Learning Analytics (LA), Educational Data Mining (EDM) research fields [23].Academic analytics uses analytics methods to meet up the wants of institutional, functional, administration, and accounting decision-making practices[82]. While the main aim of both LA and EDM is to turn raw data into actionable insights making education-related decisions better. Based on the nature of the analysis of big data in the learning environment, both LA and EDM aimed at improving quality education by improving interventions [141], [186].

Data-driven decision making has been continuously one of the essential jobs in the field of higher education. Traditionally the decisions made by the higher educational institutions faculty and administrators is based on the presumptions and certain hypothesis. This process is very time consuming and limited to the quality of higher education. From administrators to teachers and learners, education insight through LA can improve higher education institutes' performance and help them to face challenges in academia. Higher Educational Institutes see Learning Analytics as a powerful resource that worked as a mirror for them. It creates new schemes and technologies which help HEIs and researchers to gain access and genuinely recognize what is happening, how an institution is performing as a whole [143].

With the increase in the online and distance education courses, higher education needs to rotate its focus on providing 'accesses' to these courses and improve its 'quality.' In online courses, instructors missed critical visual clues that enable them to spot which students were not sufficiently challenged, bored, puzzled, or who were unable to attend the course [43]. For this, HEIs are implementing and utilizing Learning Analytics (LA) technologies to effectively recognize and support both students andteachers in the learning process [134].

Recently, the most focused key areas of researchers are the adoption of "Massive Open Online Courses (MOOCs)" and "Learning Management Systems (LMS)" platforms in the educational environment and using Learning Analytics (LA) methods for enhancing performance and student's behaviors, retention, and their recruitment. Prediction, Gamification, Social Network Analysis (SNA), Statistic, Distillation of data for Human Judgment, and Outlier Detection are the most common learning analytics used in the higher education domain [85], [188]. More importantly, the applications of learning analytics give a boost to HEIs to improve the educational experience. This applicability helps to know how the LA field is maturing in the higher education domain [30]. 
Although the utilization of learning analytics is growing at a breakneck pace in HEIs to magnify the excellence of the teaching and learning process, there occur frequent obstructions that avoid the data sets from being used analytically and efficiently. Data quality, ownership, access, organizational culture, and expert knowledge available to employ learning analytics are common questions that needed concentration [11]. Unfortunately, HEIs face various issues and challenges while implementing learning analytics applications like ethics, data privacy, protection, and quality, etc.[43] [84].

\section{RESEARCH METHODOLOGY}

The search period for literature review on LA/EDM is set in such a way that it covered publications from 2008 to 2020, exploring the status, techniques, applications, and challenges of LA/EDM in the higher education domain. The keywords and mixture of keywords that are used included "learning analytics" AND "higher education" AND "status" AND "adoption", "learning analytics" AND "issues","data mining" AND "higher education", "data analytics" OR "learning analytics", "educational data mining" OR "data mining techniques" OR "visual data mining" OR "classification" OR "regression" OR "clustering" OR "text mining" OR "association rule" OR "gamification" OR "social network analysis" AND "their applications" AND "higher education" OR "higher education institutes" OR "LMS' OR 'MOOCs" OR "online learning" OR "blended learning". Other keywords included "learning analytics" AND "applications" OR "higher education", "assessment OR "feedback" OR "prediction" OR "pedagogy" OR "curriculum" OR "social learning analytics" OR "online learning environment".

The databases searched for this systematic literature review included Association for Computing Machinery (ACM), (ERIC), IEEE Computer Society Digital Library (CDSL),SoLAR, Computers in HumanBehavior, the Internet and Higher Education, Computers \& Education, EDUCASE, Google Scholar, Science Direct, Scopus and Springer as well as the conference proceedings of the International Learning Analytics and Knowledge (LAK), Educational Data Mining.

Following research questions guided this systematic literature review:

RQ1. What is the status of learning analytics and how the field of learning analytics is growing in various countries in the higher education domain?

RQ2. How various LA/EDM techniques can be used to solve practical challenges and issues in higher education?

RQ3. What are the LA/EDM techniques best suited to these challenges?

RQ4. What are the purposes for which HEIs have applied LA/EDM techniques?

RQ5. What are the challenges and issues of deploying learning analytics in higher education domain?

For answering these research questions, a systematic literature review on the current status of LA/EDM, their techniques, classification, and challenges in the higher education context was conducted to improve the learning and teaching process.

In this paper, we have discussed the concepts of Learning Analytics (LA) and its evolution, especially in the educational field. In Section 3, Learning analytics (LA) is defined and enlightened. Section 3.1 presents the status of Learning Analytics (LA) in various countries in the higher education domain, and section 4 reviewed the utilization of LA/EDM techniques in higher education. Section 5 presents the classification of LA and consequently reviews the work related to each classification scheme.Section 6 presents the results.Section 7 discusses the challenges faced by learning analytics.The last sectionsconclude how this study is giving future directions for research and practices in the learning analytics field. We are hopeful that this literature review will shape the future of learning by using EDM and LA, as a powerful tool, for solving precise learning and teaching problems in the higher education domain. Also, this review crystallizes more precise problems that previous findings were incapable of concentrating upon. Additionally, this review provides a current and recent development to view the expansion of LA/EDM in higher education.

\section{LEARNING ANALYTICS}

In the last couple of years, Learning Analytics (LA) has been rising progressively and emerged as a separate field of research discipline. Analytics is a new tool in a new time and considered to be a practice of mining higher education institutional data sets to generate "actionable intelligence" via statistical and predictive modelling techniques with the mean of improving decision making power, student outcomes, and their success [17].

Initially, the definition of LA is given as "the use of intelligent data, learner-produced data and analysis models to discover information and social connections and to predict and advice on learning" [140]. Learning analytics is defined as "the measurement, collection, analysis, and reporting of data about learners and their contexts, for purposes of understanding and optimizing learning and the environment in which it occurs" [142].A recent definition of LA is stated as: "LA is the capability to discover patterns and associations across modalities (synchronizing talk), over time (during revisiting of studied matter), or at a micro genetic stage (showing how an educator uses analytics to examine learner activity)" [164]. An additional definition of LA is given as: "LA is the area of analytics investment and interest that is directly related to the student experience and learning outcomes with the aim at improving learner's success and student services" [15].

A systematic literature review of learning analytics by [8],shows that LA uses various methods like Visual Data Analysis techniques, Social Network Analysis (SNA), Semantic, and Educational Data Mining (EDM) to analyze the big educational data. The objectives of this literature 
review are to improve student's learning outcomes, teacher performance, personalized learning, high-quality curriculum development, and better employability. Virtual Learning Environments (VLEs), Learning Management System (LMS), Cognitive Tutors (CTs), Massive Open Online Courses (MOOCs), Web-based environments are the different learning settings used by educational research community with the objectives to improve students behavior, self-reflection, self-awareness, assessment and feedback services via LA/EDM methods. These objectives can be attained through pedagogical interventions. Interventions are an essential measurement of the learning analytics and educational data mining process, as in this step, raw data is turned into actionable intelligence [105]. For systems handling the massive amounts of data, efficient software systems are required. Testing plays a vital role in ensuring the quality and reliability of the software system [178-185].

LA will bring HEIs onto the next advanced level by making educational data patterns visible. Pedagogic behavior of the instructor and learner should also be considered to improve the learning outcomes. Other various dimensions of LA should be taken into account to promote self-reflection, curriculum development, enhance learner's performance, and increases teacher effectiveness and efficiency [56]. As the educational field is moving towards digitization, online and distance learning is becoming popular among stakeholders. The students leave digital footprints while engaging with their digital learning environment. LA intervenes in these footprints to take better decisions aimed at improving learning, teaching, and institutional effectiveness [40].

\subsection{Status of learning analytics in various countries in the educational domain}

The authors gathered the data about various projects and case studies from different sources, including International Conference on Learning Analytics \& Knowledge, International Conference on Learning Analytics in Asia, Society for Learning Analytics Research, EDUCASE, JISC, ERIC, and many more. The authors extensively and iteratively searched intercontinental databases of reliable academic resources, conferences, and issuers, including Scopus, ERIC, Google Scholar, Science Direct, DBLP, and ACM Digital Library.

After reviewing various case studies and projects in the implementation and usage of LA methods, it is observed that LA has a strong effect on changing educational practices and upgrading teaching and learning practices. Although LA is gaining attraction in the higher education domain, its advancement in Asia was hardly studied. Most of the research work in this field is done in the USA, UK, and Australia. Many of these case studies implemented showed that LA is still at its initial stage of development [137]. Countries like Romance, France, Latin America, the Table 1 provides a summary of projects and case studies to give a clear view of the status of LA around the world in a higher education context. popularity and adoption of learning analytics are limited when compared against Anglo Saxon countries. Also, due to many factors, one of them is lacking awareness of LA; the required responses are not observed from Russia, China, and India [37]. In the Third Conference on "Learning Analytics and Knowledge," almost all the authors who submitted papers are from Europe and North American countries [101].Survey findings showed that in China, most of the LA papers from 2012 to 2014 were simple literature review and general commentary rather than practical implementation and case studies [49]. Various case studies and projects in the UK, Canada, Uruguay, and Korea show the adoption and implementation of learning analytics techniques in higher education institutes. Except for the UK and Canada, several case studies showed that there is a scarceness of projects and studies expressing the state of LA [121].

European higher education institutes focus on a learning analytics-based project, the SHEILA project, to encourage formative assessment and personalized learning during the online and distributed learning process [156]. Big data and learning analytics start taking roots in American HEIs as learning and teaching methods changing with the changing technologies. Data-driven decision approaches are not silver bullets but provide solutions to higher education institutions to some extent [113]. Also, there is a need for advanced technologies and analytical tools to harness the complexity of Big data[187].

Purdue University, Indiana, aimed to boost student success and support them during their course learning and so final graduation grades by employing the power of learning analytics [6]. Introduction of learning analytics in Japanese universities lifted learning and teaching practices using features of educational big data [47]. Learning analytics has the power to make Korean higher education curricular better by providing customized learning and teaching methods [76]. Open University (OU) puts the power of LA technology to informed teachers on time. It provides flourishing interventions that will help the students to attain better outcomes [123]. A lot of research work that outlines the evolution and implementation of learning analytics in Indian higher education is not seen yet. Only a few pieces of literary works and the experimental study shows the adoption of learning analytics for improving decision making power and student learning experiences [116], [14].

Although the objective of this literature evaluation is to provide the status (i.e., adoption and implementation) of LA in various countries, significant influence and coverage of LA have been seen from USA (due to continuous research contribution from the non-profit organization, "EDUCAUSE"), UK (as "JISC', a non-profit organization which provides digital solutions for UK education and skills), Australia, and Canada. However, they can influence a deficient proportion in China, Korea, Russia, Japan, India, the Philippines, and Malaysia. 
Monika Hooda et al., International Journal of Emerging Trends in Engineering Research, 8(5), May 2020, 1626 - 1646

Table 1: Summary of projects and case studies

\begin{tabular}{|c|c|c|c|}
\hline Country & Institution & Case study/ Project & Summary \\
\hline \multirow[t]{7}{*}{ USA } & Purdue University & $\begin{array}{l}\text { Traffic Signals and } \\
\text { interventions }\end{array}$ & $\begin{array}{l}\text { Improve student's success at the course } \\
\text { level; enhance student's retention rate. }\end{array}$ \\
\hline & $\begin{array}{l}\text { University } \\
\text { of Maryland }\end{array}$ & LCMS (Blackboard) & $\begin{array}{l}\text { Traces student's activities and predict } \\
\text { their success rate; focus on early } \\
\text { intervention to improve student's } \\
\text { trajectory. }\end{array}$ \\
\hline & $\begin{array}{l}\text { New York Institute } \\
\text { of Technology }\end{array}$ & $\begin{array}{l}\text { Identifying at-risk students } \\
\text { using the STAR model }\end{array}$ & $\begin{array}{l}\text { The aim was to enhance the retention } \\
\text { rate of students by deploying a Student } \\
\text { At-Risk model }\end{array}$ \\
\hline & $\begin{array}{l}\text { California State } \\
\text { University }\end{array}$ & LMSS & $\begin{array}{l}\text { Better predict student success via } \\
\text { multiple demographic variables than } \\
\text { using traditional methods }\end{array}$ \\
\hline & $\begin{array}{l}\text { University of } \\
\text { Michigan }\end{array}$ & E2Coach & $\begin{array}{l}\text { Leveraging analytics to support } \\
\text { students with course decisions; acts as } \\
\text { an intervention engine }\end{array}$ \\
\hline & $\begin{array}{l}\text { Rio Salado } \\
\text { Community College }\end{array}$ & $\begin{array}{l}\text { PACE (Progress and } \\
\text { Course Engagement) }\end{array}$ & $\begin{array}{l}\text { Track improvement of students in } \\
\text { courses; early intervention to predict } \\
\text { at-risk students }\end{array}$ \\
\hline & $\begin{array}{l}\text { Northern Arizona } \\
\text { University }\end{array}$ & $\begin{array}{l}\text { GPS (Grade Performance } \\
\text { System) }\end{array}$ & $\begin{array}{l}\text { Student alerts for resolving their } \\
\text { educational } \\
\text { issues and enhance their success }\end{array}$ \\
\hline NETHERLANDS & $\begin{array}{l}\text { Erasmus University } \\
\text { Rotterdam }\end{array}$ & $\begin{array}{l}\text { STELA (Successful } \\
\text { Transition from secondary } \\
\text { to higher Education using } \\
\text { Learning Analytics) }\end{array}$ & $\begin{array}{l}\text { Focuses on providing formative and } \\
\text { summative feedback to students in the } \\
\text { transition; scalability and } \\
\text { transferability solutions }\end{array}$ \\
\hline \multirow[t]{4}{*}{ AUSTRALIA } & $\begin{array}{ll}\text { Edith } & \text { Cowan } \\
\text { University } & \end{array}$ & C4S (Connect for Success) & $\begin{array}{l}\text { Improved retention and success rates of } \\
\text { students }\end{array}$ \\
\hline & $\begin{array}{l}\text { University of New } \\
\text { England }\end{array}$ & $\begin{array}{l}\text { AWE (Automated Wellness } \\
\text { Engine) }\end{array}$ & $\begin{array}{l}\text { Aimed at early identification of } \\
\text { students who were struggling with their } \\
\text { study programs }\end{array}$ \\
\hline & $\begin{array}{l}\text { Open University } \\
\text { Australia }\end{array}$ & $\begin{array}{l}\text { PASS } \quad \text { (Personalised } \\
\text { Adaptive Study Success) }\end{array}$ & $\begin{array}{l}\text { Track students' performance to } \\
\text { enhance study success }\end{array}$ \\
\hline & $\begin{array}{l}\text { University } \\
\text { Wollongong }\end{array}$ & $\begin{array}{l}\text { SNAPP (Social Networks } \\
\text { Adapting } \\
\text { Practice) }\end{array}$ & $\begin{array}{l}\text { Support teacher to evaluate student } \\
\text { behavioral patterns during the course; } \\
\text { timely intervention }\end{array}$ \\
\hline \multirow[t]{6}{*}{ UK } & $\begin{array}{l}\text { University of Central } \\
\text { Lancashire }\end{array}$ & $\begin{array}{l}\text { Student performance, } \\
\text { retention, and progression }\end{array}$ & $\begin{array}{l}\text { Track student progress in } \\
\text { course; intervention }\end{array}$ \\
\hline & Open University & $\begin{array}{l}\text { Student engagement, } \\
\text { retention and progression }\end{array}$ & $\begin{array}{l}\text { Track student progress in } \\
\text { course; intervention }\end{array}$ \\
\hline & $\begin{array}{l}\text { University of East } \\
\text { London }\end{array}$ & $\begin{array}{l}\text { Student lifecycle and } \\
\text { performance benchmarking }\end{array}$ & $\begin{array}{l}\text { Track student progress in } \\
\text { course; intervention }\end{array}$ \\
\hline & $\begin{array}{l}\text { University } \\
\text { Sheffield }\end{array}$ & $\begin{array}{l}\text { Student admission and } \\
\text { progression }\end{array}$ & Student support and intervention \\
\hline & $\begin{array}{l}\text { University } \\
\text { Manchester }\end{array}$ & $\begin{array}{l}\text { Facilities and utility } \\
\text { optimization }\end{array}$ & Student support and intervention \\
\hline & $\begin{array}{l}\text { University of } \\
\text { Bedfordshire }\end{array}$ & $\begin{array}{l}\text { Student engagement, } \\
\text { retention and progression }\end{array}$ & $\begin{array}{l}\text { Track performance of students and } \\
\text { predict their success }\end{array}$ \\
\hline
\end{tabular}


"SHIELA (Supporting Higher Education to Integrate Learning Analytics)" project helps the European higher education institutions to overcome the challenges students face during the learning process in an online environment. Moreover, SHIELA project helps in building a framework that supports formative assessment and adaptive/personalized learning in the field of learning analytics. LALA project in Latin America helps to improve the quality, efficiency of HEIs and also provides the potential to employ and implement Learning Analytics to enhance data-driven decision-making processes. Another project, LACE (Learning Analytics Community Exchange), intended to assimilate different communities that provides recent and future views about learning analytics and educational data mining. According to a report of Reportlinker.com "Education and Learning Analytics Market by Application, Component, Deployment, End-User And Region - Global Forecast to 2024”, the global higher education and learning analytics status is estimated to grow from USD 3.1 billion in 2019 to USD 8.2 billion by 2024, at a Compound Annual Growth Rate (CAGR) of $21.5 \%$ [177].

\section{LEARNING ANALYTICS BASELINE}

Despite the fact, learning analytics is a beginning research line, andmuch work has been done in this field that holds up research, advancement, utilization, and application of diverse kinds of methodologies. Therefore, some of the LA/EDM theoretical background (e.g., techniques, approaches) has been traced, and the related work is outlined in this section.

\subsection{LA/EDM techniques}

The literature reviewed regarding the use of LA/EDM techniques (i.e., classification, clustering, association rules, correlation, statistics, text mining, gamification, social network analysis, and visualization) to predict, grouping, representation, and monitor diverse learning activities to enhance learners and instructors quality in the higher education environment is illustrated. The summary of this literary work is summarized in table 2 .

\subsubsection{Classification}

It is the most frequently used LA/EDM technique that helps to classify datasets into different classes. This technique has been used generally in the higher education domain for predicting student performance, behavior, and predicting/preventing students at risk of dropping out, retention in online courses/e-learning environment. The classification technique helps instructors to improve student's learning quality by allowing them to build an effective course curriculum and support learners not performing well in the course [118]. Classification technique helps in i. Detecting dropout susceptible students as early as possible from offline, online and e-learning courses [115],

ii. Evaluating students' interactions with different types of educational resources [25] [103],

iii. Predicting which learner will not complete their assignment task [38], [29],

iv. Identifying students' behavior and their motivation level during the learning process [133],[119].

\subsubsection{Clustering}

The clustering technique is used to identify data that are similar to each other. This technique helps to understand the differences and similarities between the large data sets for an easy decision. In higher education clustering technique aimed at examining-

i. Student's interaction and engagement in the learning process in LMS [21], [34],

ii. How a student interacts in diverse learning circumstances [143],

iii. Recommended learning resources to learners based on the digital footprints they leave behind during a course [75].

Additionally, the clustering technique allows the teachers to predict students learning by analyzing the log files in LMS to predict students drop out at early stages and boost their retention rate [67] to enhance learner's skill acquisition rate [128].

\subsubsection{Association rule}

It is used to establish the relationship between variables in the big sets of data items. The main motive of this technique is to discover strong learning rules (hidden patterns) using some measures (e.g., student's characteristics and their learning patterns). The discovered association rule helps in-

i. Curriculum design, knowing student's area of interest, monitoring, and analysis of their academic performance [81],

ii. Predicting student's performance using learning analytics algorithm [71], [13],

iii. Providing employment opportunity for a student by matching their profile with the organization's needs [4],

iv. Enhancing the learning process (predict student outcomes and identify which student needed extra concentration from teachers to enhance the overall success of course) based on student's characteristics extracted from logged datasets [9],

v. Association rule technique is also used for designing curriculum, for extracting the useful student's patterns to evaluate and predict their outcomes and performance and make better datadriven decisions to improve the quality of education [64], [160]. 


\subsubsection{Visual data mining}

Visual data mining is a mixture of conventional data mining techniques and visualization tools for the visual representation of patterns of data. Visual data mining technique represents the high dimensional data of the educational domain graphically, so it became easy to identify patterns and derive valuable insights. In higher education, visual data mining helps-

i. The teachers to understand how the learner's pilot in an LMS environment and monitors the students easily within a single screen [145],

ii. In supporting students' engagement during the course and also helps the tutors to monitors their behavior, contribution and performance [112], [50],

iii. The instructors get timely feedback about student's performance to evaluate the course resources and materials provided to students during their learning [87],[92].

This review also showed that using visual data mining techniques instructors be able to control the graphical representation of student's behavior or activities in order to increase a better understanding of what is happening in the learning process [100], [172], [57].

\subsubsection{Statistics}

Statistics is the traditional mathematical technique that deals with the quantification, collection, investigation, understanding, presentation, and concluding data. Several reviewed studies showed that statistics data mining technique helps in the higher education domain in-

i. Predicting student's achievement and success [22], [154],

ii. Self-regulated learning [173],

iii. Motivating students during their learning tasks [88],

iv. Student retention and success rates [32].

\subsubsection{Regression}

It is used for determining relationships between variables and also estimates how these relationships can be helpful to individuals learning outcomes. It is used in higher education to-

i. Predict student's performance [120],[153],

ii. Predict learners cognitive behavior in MOOC [161],

iii. Improve learners grade points [109], [148],

iv. Identify student's characteristics to improve the quality of HEIs to decrease students' dropout rate from the course in LMS [2], [77],

v. The regression technique can also assist in predicting student's success and behavioral engagement in higher education by building linear and multi regression models [122], [125]to improve teaching and course quality.

\subsubsection{Sequential pattern}

It is a useful LA/EDM technique for discovering sequential patterns by analyzing sets of sequential events. In higher education, a sequential pattern is used to-

i. Represents students' interactions with the MOOC courses activities to support self-regulated learning [166],

ii. Discover learner's navigational patterns [114],

iii. Acquire adequate early warning for students that helps teachers with their teaching plan understanding [174],

iv. In collaborative learning, sequential patterns are used to improve learner's cognitive understanding [83], [176], and predict student's academic performance by using the following information [93], [99] [110]. It is also used for evaluating students by utilizing their academic performance and grades, which eventually leads to better student outcomes.

\subsubsection{Text mining}

It is used for extracting interesting patterns, relationships, and knowledge from unstructured textual data. In higher education, the text mining technique is employed for mining and analyzing big unstructured text datasets to discover exciting patterns, extract useful facts, and support decision making for learners, instructors, and administrators. Text mining can be applied to-

i. Support collaborative learning by extracting cognitive information from the text to support both tutor and learner [41],

ii. Predict student's engagement based on their involvement in discussion forums in eenvironment [63], [89],

iii. Provide automatic formative assessment in elearning environment [65],

iv. Course improvement suggestions from student's feedback comments [54].

v. It is also used in enhancing understanding of online engagement and the success of students from a massive amount of digital learning data sets [46], [58].

After exploring, it is seen that higher education policymakers can apply text mining techniques to find valuable relationships and patterns by gaining insights into online discussion forums, emails, or chats to support higher education.

\subsubsection{Correlation}

The correlation technique refers to the degree of linear relationship and association between two variables. In higher education correlation technique is employed to-

i. Assess student's engagement and their academic learning outcomes in online learning [7], 
ii. Characterized patterns to analyze student's interaction with the MOOCs discussion forums [27],

iii. Help the instructor to prepare course activities or for receiving feedbacks regarding the most accessed course materials [5],

iv. Identify and analyze students behavior in online courses using their clicking patterns [150],[158], [175],

v. Investigated studies showed that the correlation technique has the power to inspect the psychometric characteristics of the students and also assess students, which helps the teachers to monitors student's progress in an ongoing course [48].

It is concluded that correlation can be efficiently used to correlate and find patterns between student's knowledge and their outcomes so that they can learn according to their learning skills and mould strategies accordingly.

\subsubsection{Outlier detection}

The outlier detection technique helps detect rare learning actions or useful observations from large datasets. By reviewing various studies, it is observed that in the field of higher education, outlier detection has very little applicability. Only a few studies had reflected on this technique, which helps in analyzing students learning difficulty, solve students learning problems by identifying irregular learning patterns, identify deviations in the teacher's and student's behavior or activities during the course [111], [126], [146].

\subsubsection{Social network analysis}

Social network analysis has emerged as a key technique of qualitative and quantitative analysis of a social network. It maps and evaluates the relationship between various information entities (e.g., humans, groups, organizations, etc.). In higher education, SNA helps to-

i. Improve and enhance career success vision of learners [73],

ii. Import and support high-quality teaching [90],

iii. Uncover the role of teachers and learners and predict their performance in the online learning environment [72],[130],

iv. Monitor the collaborative learning process and by intervening to discover improvement areas and their degree of participation in the course [104], [129].

Based on these, it can be said that SNA is a robust framework for the analyses of learner's social behavior, enhancing learners learning outcomes in online courses, and the relationship between the learners and their teachers.

\subsubsection{Gamification}

Gamification is a technique which is a set of activities and methods that uses games technicalities or games design process to solve problems. Research findings showed that gamification is used to-

i. Improve cognitive, motivational and behavioral learning outcomes [86], [127],

ii. Motivate students to increase the course success rate by decreasing dropout rates [16], [51],

iii. Enhance student's engagement in MOOCs[163],

iv. Smooth the formative and summative assessment process to promote better student learning [68].

Table 2: The application of LA/EDM techniques in higher education

\begin{tabular}{|l|l|l|}
\hline S.no & Techniques/Approaches & Examples \\
\hline $\mathbf{1}$ & Classification & {$[25],[29],[38],[103],[115],[118],[119],[133]$} \\
\hline $\mathbf{2}$ & Clustering & {$[21],[34],[67],[75],[128],[143]$} \\
\hline $\mathbf{3}$ & Association rule & {$[4],[9],[13],[64],[71],[81],[160]$} \\
\hline $\mathbf{4}$ & Visual data mining & {$[50],[57],[87],[92],[100],[112],[145],[172]$} \\
\hline $\mathbf{5}$ & Statistics & {$[22],[32],[88],[154],[173]$} \\
\hline $\mathbf{6}$ & Regression & {$[2],[77],[109],[120],[122],[125],[148],[153],[161]$} \\
\hline $\mathbf{7}$ & Sequential pattern & {$[83],[93],[99],[110],[114],[166],[174],[176]$} \\
\hline $\mathbf{8}$ & Text mining & {$[41],[46],[54],[58],[63],[65],[89]$} \\
\hline $\mathbf{9}$ & Correlation & {$[5],[7],[27],[48],[150],[158],[175]$} \\
\hline $\mathbf{1 0}$ & Outlier detection & {$[111],[126],[146]$} \\
\hline $\mathbf{1 1}$ & Social network analysis & {$[72],[73],[90],[104],[129],[130]$} \\
\hline $\mathbf{1 2}$ & Gamification & {$[16],[51],[68],[86],[127],[163]$} \\
\hline $\mathbf{1 3}$ & Distillation of data for human & {$[1],[55],[149]$} \\
\hline $\mathbf{1 4}$ & Judgment & {$[52],[80]$} \\
\hline
\end{tabular}


By reviewing various studies related to LA/EDM techniques, it is concluded that classification is the most frequently used technique followed by clustering, whereas, a distillation of data for human Judgment, a discovery with models are the techniques which are applied rarely. The choice of techniques entirely relies on the problem type of problem.

\section{CLASSIFICATION OF LEARNING ANALYTICS}

The implementation of Learning Analytics (LA) in higher education is to practice diverse goals related to various stakeholders (learners, teachers, researchers, administrators) and their learning and teaching framework, to improve and enhance learning outcomes. This section summarizes the literature to classify learning analytics according to its applicability in educational settings. The categorization is done into six larger scopes, which are outlined in this section as follows.

\subsection{Assessment}

Assessment plays a very fundamental role in higher education for measuring the effectiveness and quality of education offered by institutions. The authors in [170] discuss various assessment approaches that fit in the context of Massive Open Online Courses (MOOCs) from both formative and summative assessment perception. The authors in[94] highlight the conventional assessment techniques (e.g., comprehensive type, discussion board, reflective focused, and project-based) in online courses. They quantitatively and qualitatively visualize the data by using learning analytics tools like tableau, Many eyes, etc. The aim of visualizing the data is to detect useful patterns of information that help the instructor in a data-driven decisionmaking process.

The authors proposed a SODAS framework in [33] that recognizes that computer-based assessment fosters more effective learning as compared to traditional paper-based assessment. Learner engagement, enrollment, and metacognition have been enhanced in the canvas learning management system by implementing formative assessment and regular feedback. True/False, multiple-choice questions, multiple dropdown questions, matching questions, multiple answers, formula, and fill in multiple blanks are the formats for assessing students. The authors in[35] proposed a grading tool known as Learning Analytics Enriched Rubric (LAe-R). In this approach, LAe-R can automatically assign grade or score to each criterion related to collaborative interactions and student's study behavior in a Moodle course. It helps the teacher to assess individual student's performance and the average performance of all the students in the course. Also, the authors in [128] presented a $\mathrm{K}$ means algorithm for analyzing student's behavior and create clusters according to the performance of students observed during the formulation of scientific questions. The purpose of the proposed algorithm is to determine strategies that strengthen scientific competences for both students and teachers.
According to the authors in [169], the current assessment in CSCL (Computer-Supported Collaborative Learning) is time-consuming and does not support reliability, validity, and individual accountability issues. They proposed a clustering algorithm through the lens of learning analytics that automatically assesses student's performance in an online learning environment to support both learners and teachers. The proposed algorithm assesses strengths and weaknesses in individual student's involvement in collaborative activities, thus accelerate the assessment method.

Furthermore, the authors in [171]proposed a learning analytics framework to forecast student's success by assessing the learning activities in the Moodle LMS environment. The proposed framework can be applied in both offline and online environments. The authors in [36] implemented a mathematical model in Moodle LMS (Learning Management System) for peer assessment using learning analytics. They use scoring rubrics for quality assessment, which overcomes the problem of past researches, i.e., validity and reliability issues. Reference [10] proposed a new method for performing a scalable qualitative assessment of wiki assignments, based on qualitative selfand peer-assessment of wiki contributions. Positive results are observed on the scalability issue.

Furthermore, many indicators have been polished relative to the skill to work collaboratively. The authors in [135] derived a framework based on the assessment theory and related feedback concepts to support self-regulated learning processes through the lens of LA.Relevant concepts of assessment, assessment design, and timely feedback have been derived coupled with current perspectives on LA and have also introduced in the results. In work by [152] implemented LA in a digital learning environment to support less adaptive learners. The proposed framework adds a 'student's learning dispositions' source to make feedback more actionable in order to improve the learning of underperforming students.

\subsection{Feedback}

If the assessment is the "engine that drives learning, feedback is the oil that lubricates the mechanism of understanding" [117]. The authors in [102] provide a feedback mechanism to avoid the dropout rate to some extent in a blended learning course. Student's online learning activities have been analyzed by using learning analytics in order to provide feedback to both the students and the teachers to advance the quality of online learning and teaching. In the study conducted by[106] deal with the concept of personalized feedback by using a learning analytics-based method. He studied the scalability issue of quality feedback in the higher education system, thus making it difficult to advance the learning process. He presents a novel learning analytics approach in which student's activities are used as indicators for instructors to provide feedback tolarge student groups through personalized messages.

The authors in [107] also provided a focus on various approaches to feedback in learning analytics. LA/EDM is 
still exploring how to address challenges in providing highquality feedback to big student groups in higher education and propose innovative patterns in which feedback is equally scalable and useful. The authors in [96] present four central variables: Difficulty, Easy, Boring, and Engaging (DEBE), a novel feedback approach to inform teachers about their learning theories and advance old ones in order to reflect whether the students found the lecture to be Difficult/Easy and Boring/Engaging. This DEBE feedback approach highlights the pedagogical potential of datasets through the learning analytics tool. In the study conducted by authors [132] explores the advantage of formative feedback methodology using learning analytics to overcome the missing elements like student retention and course success rate.

Moreover, this methodology can adequately handle the scalability and implementation cost issues well to support student learning. The authors implemented a novel tool in [70] for generating and promoting feedback for teachers popularly known as LOCO-Analyst. Moreover, the proposed approach also explains different tools and aids learners are turning to and can offer different types of feedback to teachers/tutors to improve the learning process. The authors in [60] explore various challenges of feedback in the higher education field. They noticed three categories of challenges: 1) feedback practices (connected with the communication of feedback comments), 2) contextual constraints (related with institutional constraints like time and scalability of feedback practices) and 3) individual capacity (related with attitudes and capabilities of students and staff) that students and staff experienced.

The authors in [20] proposed a content analysis of feedback text provided by instructors in the online course based on different indicators of beneficial and reliable feedback. It is found that good quality feedback helps to improve students' self-regulated learning. The authors in [152] have demonstrated that Dispositional Learning Analytics (DLA) not only predict students at risk but also provide both students and teachers with actionable feedback. Moreover, the proposed approach also analyze the cognitive, metacognitive, engagement, emotions, and motivation factors of students, help in providing actionable feedback, and designing effective interventions.

\subsection{Prediction}

Learning analytics in higher education predicts difficulty faced by the students during their learning process to offer appropriate guidance or recommendations to precise needs supported by actionable intelligence. The authors in [168] present a model for predicting student's performance by blending LA/EDM and Genetic Programming (GP) approach. The model performs better than conventional models in terms of prediction pace and interoperability. The model is somewhat detrimental to quality and is being worked upon. The authors proposed a new prediction system in [3] to identify at-risk students early in their courses.

Moreover, they designed timely interventions for students with low academic performance to help students in enhancing their performance. The authors in [26] developed a model to predict students at risk of dropping out in MOOCs based on their learning patterns and behavior. They noted that in traditional educational institutions dropout rate can be visible at the end of the courses; their model overcomes this pitfall. In work by [165], the authors focused on utilizing the concept of learning analytics in Virtual learning Environment (VLE) for predicting student's dropout rates to improve student retention. Based on the student's current VLE activities and previous learning behavior, they build their prediction model. Another researcher in[18],presents an early warning system for poor performers during the course by employing a learning analytics concept.

Effective interventions should be provided by them in their study to improve prediction accuracy. The authors in [61] evaluated the use of Predictive Learning Analytics (PLA) data by teachers to predict student's performance and allow them to predict students at risk of dropping out. Moreover, in this approach, the impact of teacher interventions on student's improvement and retention rates is also examined. The authors in [98]analyzed the influence of diverse factors in the prediction of student's performance in MOOCs. Their analysis results showed that MCQs are easier to predict than coding questions, and the final exam grade is tougher to predict than the final grade. Besides, there are some limitations of their work related to students filtering concept and analysis process. In the study conducted by authors[69] presented a method of learning analytics to study student agency ("illustrates important components of intended, determined, and significant learning") in higher education. The purpose of this approach is to improve student's selfassessed capabilities as learners and inform pedagogical practices to teachers to manage and optimize learning.

\subsection{Curriculum}

The current status of employment of LA in the higher education field shows whether the features of the curriculum are performing as intended. The authors in[39] implemented an approach that assists faculty in using learning analytics for course/curriculum designing by using the necessary big data sets. Based on their approach, they explore the data sets appropriate to the course/curriculum design via analysis tool; this analysis is not possible with current course/curricular design methods. The authors in [53]propose an automated general curriculum analytics framework that determines the efficiency of the curriculum by evaluating the curriculum via learning analytics. They also explore the advantages and disadvantages of the framework that came up with new oversight of research in curriculum evaluation and design, improves student retention rates, understanding student's feedback, improve skills of students for better placement. In the study conducted by authors [97] presents a scalable approach for designing and evaluating the online K-12 curriculum and its fundamental pedagogical framework using learning analytics. This approach offers exciting opportunities to power the curriculum and the data available to improve both the teaching and learning process. The authors in [95] discuss various learning analytics techniques that permit the teachers to assess the curriculum design and 
provide insight on possible difficulties students facing during the program. In this approach, they discuss opportunities for improving the curriculum design or set of analytics tools for curriculum (re)design. Reference The authors proposes a RISE (Resource Inspection, Selection, and Enhancement) framework in [12] for using LA to facilitate the continuous improvement of the course curriculum. This approach is inexpensive and efficient as it may guarantee further evaluation schemes to recognize why students ignore course resources or why the resource is not contributing to successful student outcomes. The authors proposed a risk management approach in [167], where they empower teachers to make data-driven decisions in curriculum and program quality improvement. Based on the online feedback system, they build their system to address risk. Their risk management framework approach and its associated features are still evolving. The authors in [62] developed a CA (Curriculum Analytics) tool: "The Integrative Learning Design Framework" that helped staff to collect information for curriculum decision making, and help in continuous curriculum improvement. The authors in [155] presented a multi-module model that helps in curriculum improvement in the e-learning environment using a K-means algorithm. Moreover, the presented model also helps to improve cognitive states and behavior of learners in order to support them and further enhance their learning experience.

\subsection{Pedagogy}

Recently in the higher education sector, pedagogical changes are seen in the teaching and learning process due to population growth and inclusion of "Quality Education." Based on the review, it is seen in all the discussionsthat pedagogical responses and strategies are emerging. Reference [138] deals with the concept of cognition using learning analytics methods in an entirely new way. They attempt to study the cognitive features in YouTube's educational videos to determine the quality of these videos by means the viewer's rating way, thus help out students and instructors recognize higher-quality videos before viewing them. The authors in [79] present a pedagogical framework for learning analytics on collaboration from the perspective of inquiry-based tasks. They observed that the formulation of a pedagogical framework is more practical through learning designs. Their findings revealed that this framework provides clarity in the learning procedure and helps teachers to improve the learning practices further. The authors in [78] depicted a relationship between learning analytics, epistemology, pedagogy, and assessment.

Moreover, they provide learners the concept of framework, reliability, validity, certainty, and connectedness of data to support them during their learning process. The authors in their work in [159] explore the relationship between learning behavior and learning progress by gaining insights into student's activities in MOOCs. Furthermore, their approach can support learning processes and improve the pedagogic quality of MOOCs. LA can analyze patterns to offer necessary improvements needed in course materials; however, pedagogical awareness is essential to specify how to advance these course materials. According to authors in [124], learning analytics algorithms aiming to monitors, measure, unpack, and understand learner's emotions. Their study has a positive impact on different teaching, learning styles, and strategies as emotions affect learner's motivation, behavior, cognition, and pedagogical issues. In work by [147], the authors explore the effect of learning analytics in motivating students by looking at their online reading behavioral patterns.

Moreover, they provide recommendations to both tutors and researchers for the future design of online learning courses to develop better teaching strategies. In the study conducted by authors [66] implemented a rubric for classifying cognitive phases in MOOC discussions messages. The authors in [42] designed a collaborative dashboard: Emodash, for showing awareness of learners' emotions in an online learning environment (video-conferencing language). Moreover, visualization of learners' emotions enhances instructors' self-awareness power and reflection.

\subsection{Social learning analytics}

Learning analytics can be implemented to explore a learner's footprints they leave on several digital social platforms (e.g., online discussions, Facebook, Twitter) to assess the reimbursement of social learning. These consist of virtual spaces or environments of both formal or informal types, the different social media and assets, measurement tools, and others, all of which include a student's personal/adaptive learning environment. Adaptive learning systems make an effort to provide personalized learning content and activities to fulfill the individual necessities of learners as they proceed through their learning process. The authors in [19] discuss HEIs have successfully implemented gamification techniques using learning analytics to motivate, engage learners, noticed behavioral outcomes of learners to advance their adaptive/personalized experiences. According to the authors in [139], social learning analytics focuses on five extensive kinds of social learning analytics. It presents the probability of recognizing interventions that can upgrade the capability of the social network to support and promote the learning process.

The authors proposed a new approach in [74] that uses the learning analytics fuzzy clustering approach to uncover hidden patterns into online social networks of learners with self-declared career willingness.

Additionally, their approach provides indicators and ways for higher education institutions to intervene so positively shape the career readiness of graduates. The authors in [31] explore student's learning styles and their collaboration in online learning through the viewpoint of social learning analytics to better understand student's interaction, behavior, and performance. The authors in[130] present the implementation of social learning analytics indicators to predict learner's performance in an online problem-based learning environment. Moreover, this approach helps in enhancing student's interactivity in the course and 
encouraged their participation. The authors in [131] implemented learning analytics techniques using SNA (Social Network Analysis) to investigate both learners' and instructors' variables (e.g., extent of interactions, uniform participation, reciprocity, group cohesion, etc.) that could help monitor and proactively assist PBL (Problem Based Learning) groups. Furthermore, this approach helps in achieving better learning outcomes in PBL.

Table 3: Classification of Learning Analytics according to its applicability in Educational Settings (2014-2020)

\begin{tabular}{|c|c|c|c|c|}
\hline S.no & $\begin{array}{l}\text { Category of LA } \\
\text { application }\end{array}$ & References with year & Learning Environment & $\begin{array}{l}\text { Techniques/Approaches/ } \\
\text { Tools }\end{array}$ \\
\hline \multirow[t]{8}{*}{1} & \multirow[t]{8}{*}{ Assessment } & [94], 2016 & $\begin{array}{l}\text { Course taught at a south-eastern } \\
\text { university in the United States }\end{array}$ & $\begin{array}{l}\text { Descriptive Statistics, Social Network } \\
\text { Analysis, } \\
\text { Content Analysis }\end{array}$ \\
\hline & & [128], 2016 & $\begin{array}{l}\text { System engineering program of } \\
\text { the University of Cordoba in } \\
\text { Colombia }\end{array}$ & K-means clustering algorithm \\
\hline & & [36], 2016 & MOOCs & Scoring Rubrics \\
\hline & & [171], 2016 & Moodle LMS & $\begin{array}{l}\text { Course mapping and Social Network } \\
\text { Analysis (SNA) for visualization }\end{array}$ \\
\hline & & [10], 2018 & Wiki-based & Assess Media Wiki (AMW) tool \\
\hline & & [33], 2019 & $\begin{array}{l}\text { Canvas Learning Management } \\
\text { System (LMS) }\end{array}$ & $\begin{array}{l}\text { STEM-Optimal Digitized Assessment } \\
\text { Strategy (SODAS) }\end{array}$ \\
\hline & & {$[152], 2019$} & Blended learning environment & $\mathrm{K}$-means cluster \\
\hline & & [135], 2020 & Digital learning environment & $\begin{array}{l}\text { Principle-based assessment designs } \\
\text { approach }\end{array}$ \\
\hline \multirow[t]{6}{*}{2} & \multirow[t]{6}{*}{ Feedback } & 132], 2017 & $\begin{array}{l}\text { logs of Learning Management } \\
\text { Systems (LMS) }\end{array}$ & $\begin{array}{l}\text { Computer analytical methodology } \\
\text { represented as a directed graph }\end{array}$ \\
\hline & & {$[96], 2019$} & $\begin{array}{l}\text { Laboratory environment with } \\
\text { pre-recorded lecture video }\end{array}$ & Mobile device with DEBE feedback \\
\hline & & [60], 2019 & $\begin{array}{l}\text { Students and educator's data } \\
\text { from two Australian universities. }\end{array}$ & $\begin{array}{l}\text { Inductively derived coding framework } \\
\text { and thematic analysis }\end{array}$ \\
\hline & & [106], 2019 & Learning Management System & $\begin{array}{l}\text { Create quasi } \square \text { immediate personalized } \\
\text { feedback messages and comparison has } \\
\text { done using ANOVA }\end{array}$ \\
\hline & & {$[20], 2020$} & Online learning & Random forest classifier \\
\hline & & {$[152], 2020$} & Blended learning (E-tutorials) & Correlation \\
\hline \multirow[t]{5}{*}{3} & \multirow[t]{5}{*}{ Prediction } & [26], 2016 & MOOC & linear regression \\
\hline & & {$[18], 2017$} & $\begin{array}{l}\text { SOCS (Shared Online CPU } \\
\text { Simulator) }\end{array}$ & Classification \\
\hline & & [61], 2019 & Distance learning & Logistic regression, visualization \\
\hline & & [69], 2020 & Finnish University courses & $\begin{array}{l}\text { Unsupervised robust clustering and } \\
\text { feedforward neural network }\end{array}$ \\
\hline & & {$[98], 2020$} & MOOC & $\begin{array}{l}\text { Regression, Support Vector Machines, } \\
\text { Decision Trees, Random Forest }\end{array}$ \\
\hline \multirow[t]{6}{*}{4} & \multirow[t]{6}{*}{ Curriculum } & [97], 2014 & Online K-12 & Correlation, Visualisations (Heat Maps) \\
\hline & & {$[95], 2014$} & $\begin{array}{l}\text { Computer Science program at } \\
\text { ESPOL (University in Ecuador) }\end{array}$ & $\begin{array}{l}\text { A statistical and computational } \\
\text { technique }\end{array}$ \\
\hline & & [167], 2016 & Online feedback system & Visualization \\
\hline & & [12], 2017 & $\begin{array}{l}\text { Open Educational Resources } \\
\text { (OER) }\end{array}$ & $\begin{array}{l}\text { RISE (Resource Inspection, Selection, } \\
\text { and Enhancement) Framework }\end{array}$ \\
\hline & & {$[62], 2020$} & Latin American university course & 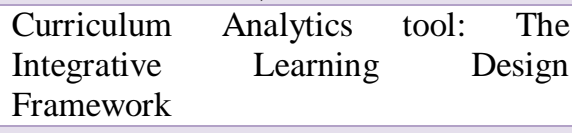 \\
\hline & & {$[155], 2020$} & E-learning & K-Means Algorithm \\
\hline \multirow[t]{3}{*}{5} & \multirow[t]{3}{*}{ Pedagogy } & {$[147], 2018$} & Online learning & $\mathrm{K}$-means clustering \\
\hline & & [159], 2018 & MOOC & Process mining, Clustering \\
\hline & & {$[66], 2020$} & MOOC & Manual- classification Rubric \\
\hline
\end{tabular}




\begin{tabular}{|c|c|c|c|c|}
\hline & & {$[42], 2020$} & Online learning & Visualization (Emodash dashboard) \\
\hline \multirow[t]{4}{*}{6} & \multirow[t]{4}{*}{$\begin{array}{l}\text { Social Learning } \\
\text { Analytics }\end{array}$} & [74], 2015 & $\begin{array}{l}\text { VLE (Virtual Learning } \\
\text { Environment) }\end{array}$ & Fuzzy Clustering \\
\hline & & {$[31], 2017$} & $\begin{array}{l}\text { Course in Primary Education at } \\
\text { the University of Murcia (Private } \\
\text { classroom group set up on } \\
\text { Facebook) }\end{array}$ & $\begin{array}{l}\text { Statistics packages and Network } \\
\text { analysis tools }\end{array}$ \\
\hline & & [130], 2018 & $\begin{array}{l}\text { Online PBL (Problem Based } \\
\text { Learning) }\end{array}$ & $\begin{array}{l}\text { Regression models, Correlation, } \\
\text { Visualisation }\end{array}$ \\
\hline & & {$[131], 2020$} & $\begin{array}{l}\text { Online PBL (Problem Based } \\
\text { Learning) }\end{array}$ & $\begin{array}{l}\text { Correlation and Multiple Regression } \\
\text { with SNA measures }\end{array}$ \\
\hline
\end{tabular}

The above table shows the purpose and applicability of LA/EDM techniques in the higher education domain. The results of the table show that learning analytics and educational data mining techniques can be used in assessment, feedback, prediction, curriculum, pedagogy, and social learning areas along with their learning environment and techniques/tools used. It is observed that the LA/EDM techniques can play a significant role in today's digital revolution to improve assessment services, feedback, and recommendation facilities, predict learners performance, their drop-out rate for the success of a course, help in designing and improving curriculum for both learners and instructors, support pedagogy related issues (e.g., cognitive states, motivation, and emotions), and enhance learners collaboration and self-regulation in a social learning environment.

\section{RESULTS}

The previously conducted researches were not able to show fresh and novice comprehensive overview of LA/EDM in the higher education domain. This systematic literature review provides an investment in LA/EDM by the higher education domain around the world that will direct to enhance performance and outcomes for students, teachers, HEIs, and immense society. This study will show a good sign of improving and empowering the higher education system to take the necessary actions and proceedings on time. The tables show an increased awareness of the topics of the review. For research purposes, a non-statistical method is used to evaluate and interpret the findings of the collected studies.

The research strategy followed showed that most of the published case studies are exploratory or experimental studies. Some of them are evaluation studies, while others are empirical studies or surveys. Based on the systematic literature review, the above sections have answered all the research questions of this study.

\section{ISSUES AND CHALLENGES IN LEARNING ANALYTICS}

After going through the existing literature systematically, this section concludes the challenges which higher education domain faces in the application and implementation of learning analytics. Numerous challenges limit the scope and adoption of LA. There are severe and repeated concerns over privacy protection, transparency, data security, ethical boundaries, data analysis issues like scalability, lack of pedagogy-based strategies. According to [24], [44], [84], there are different ethics and privacy concerns in the digital context, as ethical and privacy issues are complicated by the fact that the big data sets available for the function of learning analytics are continually expanding. Researchers began to show more interest related to privacy and ethical issue in the field of LA [59], [108], [144], [157].

Many policies have been created to show awareness that higher education institutions needed to improve the applications of learning analytics within legal and ethical frameworks. The Open University in the UK was one of the first universities to establish a code of practice in 2014, followed soon after by a code of practice developed by JISC in 2015, an organization that provides advice on digital technology for education and research in the UK. Later, The DELICATE Checklist framework was designed in 2016 for the ethical treatment of data in the learning analytics field [28]. Transparency and consent are other issues that arise around the implementation and use of learning analytics [136]. Pedagogy based approaches are ignored as part of the strategy for learning analytics and institutions focused only on addressing technical challenges [91]. In the intervening time, [162] presents the technical and analytical challenges posed by big data sets when using a scalable approach to better support student's learning in the digital environment.

\section{LIMITATIONS OF THIS STUDY}

This study has several limitations, which may be seen as the potential for future research. First, this study does not explore the actual utilization of theories and real-time application of some technologies. In consequence, to thoroughly understand what theories have been used and in what ways concerning the development of the LA research area and its impact on higher educational practice. Secondly, it is challenging to find the papers related to pedagogybasedapproaches, and a shortage of studies empirically justifying the effect of analytics triggered interventions. Lastly, in this study, the papers presented at the International conferences on Learning Analytics in Asia and some other popular conferences which have also done work in the LA field have been excluded from the review process, as those 
are scheduled to take place after the review process. However, it is decided to include recently published journal articles (published from 2008 to Feb 2020) even with fewer citations to indicate the current trends in this domain.

\section{CONCLUSION}

This literature review aims to look over the concepts which have been used in implementing learning analytics to support and enhance study success. HEIs are employing learning analytics to improve the services and resources they provide, to improve visible and non-measurable targets of learners such as grades, pedagogy, emotions, learning behavior, and retention and help educators in improving their teaching practices. The paper tries to enlighten the roots, essence, application, and classification and key challenges in the LA field.

RQ1. What is the status of learning analytics and how the field of learning analytics is growing in various countries in the higher education domain?

Table 1 provides a clear answer to the first research question about the status of LA around the world in a higher education context. Based on the LA projects and case studies reviewed for various countries, we disclose the evolution and current status of LA in various countries, which are not concentrated on in the previous studies. It is observed that the higher education and learning analytics significance is multiplying rapidly during the period 2008 to 2020 globally, with the rising need for data-driven decisions for improving the quality of education and the growing adoption of advanced technologies across the higher education sector.

RQ2. How various LA/EDM techniques can be used to solve practical challenges and issues in higher education?

Table 2 in this study can support HEIs in determining the exact technique for the right use. In contrast, previous studies have mainly used limited techniques for solving practical challenges and issues in higher education. Techniques such as "Classification", "Clustering", "Association Rule Mining", "Correlation", "Visualisation", and "Statistics" have been recurrently used to identify students behavior and their motivation level during the learning process, student's interaction and engagement in the learning process, course improvement suggestions from students feedback comments, and empower teachers to make data-driven decisions in curriculum and program quality improvement.

Several of these techniques are frequently used to identify and detect students' unusual behaviors in different learning activities to improve their retention rate and self-regulation, to extract the useful student's patterns to evaluate and predict their outcomes and performance and make better data-driven decisions to improve the quality of education.

Moreover, learning in social dimensions and pedagogy related issues (e.g., sentiment and emotion analytics) are also explored in this study using "Gamification" and "Social Learning Analysis" techniques, which are a black box in previous studies. Gamification and Social Learning Analysis are emerging techniques that have been recognized for their positive impact on both learners and instructors. The conclusions from these processes can empower the HEIs to take the required measures and actions in an appropriate and timely manner.

RQ3. What LA/EDM techniques are best suited to these challenges?

The discussion based on the application and implementation of LA/EDM can present significant advantages to both learners and educators, and therefore recommend HEIs to adopt them where sufficient. The choice of which technique to employ or apply generally depends on the nature/category of the problem to be resolved. For example, various research works have been practicing the employment of LA/EDM techniques to assess, predict, and monitor student performance and their engagement, providing necessary timely feedback and recommendations in the course using techniques such as classification, clustering, regression, gamification, association rule mining, visual data mining, correlation, and social learning analysis.

RQ4. What are the purposes for which HEIs have applied LA/EDM techniques?

It is observed from the review (Table 3 ) that the purpose of LA/EDM techniques for HEIs is to improve assessment services, feedback, and recommendation facilities, predict learners performance, their drop-out rate for the success of a course, help in designing and improving curriculum for both learners and instructors, support pedagogy related issues (e.g., cognitive states, motivation, and emotions), and enhance learners collaboration, and self-regulation in a social learning environment, increase students engagement in learning course, enhance their retention rates and grades. From the review papers MOOCs, VLE (Virtual Learning Environment), Wikis, LMS (Learning Management System), Online learning, E-learning, Social learning (e.g.,Facebook, Twitter), YouTube videos, classroom courses are the most common learning environments.

RQ5. What are the challenges and issues of deploying learning analytics in higher education domain?

Finally, we present the future directions, with a vision of challenges that need attention, including scalability, privacy, data ownership, and ethics of LA. Many policies have been created to show awareness that higher education institutions needed to improve the applications of learning analytics within legal and ethical frameworks.

The Quality of work reviewed from individual researchers to global joint efforts and well-known research organizations (such as SoLAR, ERIC, EDUCAUSE, and LAK) can collectively present an incredible influence to have a significant impact on the type of researches to empower new directions in the learning analytics field. 


\section{FUTURE DIRECTIONS}

Learning analytics is a fast-growing platform, and HEIs are adapting to it to go beyond the conventional method of analysis and respond to innovative improvements in the area as they take place. Three techniques that are being applied in learning contexts: discourse analytics, social network analysis, and sentiment and emotion analytics has evolved over numerous years; however, they have recently been introduced into LA. This will assist educators in improving their courses and furnishing learners with innovative ways to understand and enhance their learning.

Furthermore, there are various challenges and issues concerned with the field of learning analytics. Further research should be undertaken in the following areas:

i. Work in the area of ethics, data protection, and privacy should be done in more detail by identifying different examples to reap the benefits of LA.

ii. There is a need for new approaches to be revisited and update policies and frameworks in learning fast-moving analytics areas as technology systems and approaches to data analytics evolve and change.

iii. There is a requirement of better curricula and pedagogical strategies to give the power to design future e-learning courses to be developed.

iv. The success of the online courses is influenced by the assessment techniques and feedback services provided. Useful metrics to asses these online courses will enhance the efficiency of these courses.

v. It is observed that the low completion rate of MOOCs (e.g., Coursera, EdX, Udacity, and FutureLearn) is often a problem in the learning analytics field. This is because there is a lack of motivation, metacognition, self-regulated learning techniques, vocational skills, and criterion-based assessment, so attention should be required in this area, which otherwise leads to the failure of MOOCs.

vi. Scalability is a crucial issue in the LA field as the learner's data is growing at a swift pace due to the digital revolution.

\section{REFERENCES}

1. S. Aguilar, S. Lonn, andS.D. Teasley. Perceptions and use of an early warning system during a higher education transition program, in Proc. of the fourth international conference on learning analytics and knowledge, 2014, pp. 113-117.

https://doi.org/10.1145/2567574.2567625

2. H. S. Akareem, andS. S. Hossain. Determinants of education quality: what makes students' perception different?,Open Review of Educational Research, Vol. 3, no. 1,pp. 52-67, 2016.

3. G. Akcapinar, M. N. Hasnine,R. Majumdar, B. Flanagan, and H. Ogata. Developing an early-warning system for spotting at-risk students by using eBook interaction logs,Smart Learning Environments, Vol. 6, no. 1, pp. 4, 2019.

https://doi.org/10.1186/s40561-019-0083-4

4. N. Alangari, and R. Alturki. Association Rule Mining in Higher Education: A Case Study of Computer Science Students, Smart Infrastructure and Applications, pp. 311-328, 2020.

5. A. AlJarrah, M. K. Thomas, and M.Shehab(2018). Investigating temporal access in a flipped classroom: procrastination persists, International Journal of Educational Technology in Higher Education, Vol. 15, no. 1, pp. 1, 2018.

https://doi.org/10.1186/s41239-017-0083-9

6. K. E. Arnold, and M.D. Pistilli (2012). Course signals at Purdue: Using learning analytics to increase student success in Proc. of the 2nd international conference on learning analytics and knowledge,2012, pp. 267-270.

7. M. Atherton, M. Shah, J.Vazquez, Z.Griffiths, B. Jackson, andC. Burgess, et al. Using learning analytics to assess student engagement and academic outcomes in open access enabling programmes, Open Learning: The Journal of Open, Distance and eLearning, Vol. 32, no. 2, pp. 119-136, 2017.

8. J. T. Avella, M.Kebritchi, S. G. Nunn, and T. Kanai. Learning analytics methods, benefits, and challenges in higher education: A systematic literature review,Online Learning, Vol. 20, no. 2, pp. 13-29, 2016.

https://doi.org/10.24059/olj.v20i2.790

9. R. Avlijas. A guide for association rule mining in moodle course management system, International Scientific Conference on ICT and E-Business Related Research, 2016, pp. 56-61.

10. A. Balderas, M.Palomo-Duarte, J. M. Dodero, M. S. Ibarra-Sáiz, and G.Rodríguez-Gómez. Scalable authentic assessment of collaborative work assignments in wikis,International Journal of Educational Technology in Higher Education, Vol. 15, no. 1, pp. 40, 2018.

11. J. Bichsel. Analytics in higher education: Benefits, barriers, progress, and recommendations,EDUCAUSE Center for Applied Research, 2012.

12. R. Bodily, R. Nyland, and D. Wiley.The RISE Framework: Using Learning Analytics to Automatically Identify Open Educational Resources for Continuous Improvement,The International Review of Research in Open and Distributed Learning, Vol. 18, no. 2, 2017.

https://doi.org/10.19173/irrodl.v18i2.2952

13. S. Borkar, andK. Rajeswari. Predicting students academic performance using education data mining,International Journal of Computer Science and Mobile Computing, Vol. 2, no. 7, pp. 273-279, 2013.

14. D. Boulanger, J.Seanosky, V. Kumar, K. Panneerselvam, and T. S. Somasundaram. Smart learning analytics,in Emerging issues in smart learning,Berlin, Heidelberg, 2015, pp. 289-296. 
15. D. C. Brooks, and T. L. B. Thayer, T. L. B. Institutional analytics in higher education, inResearch report, ECAR, 2016.

16. P. Buckley, and E. Doyle. Gamification and student motivation, Interactive learning environments, Vol. 24, no. 6 , pp. 1162-1175, 2016. https://doi.org/10.1080/10494820.2014.964263

17. J. P. Campbell, P. B.DeBlois, and D. G. Oblinger (2007). Academic analytics: A new tool for a new era,EDUCAUSE review, Vol. 42, no. 4, pp. 40, 2007.

18. K. Casey, and D.Azcona. Utilizing student activity patterns to predict performance,International Journal of Educational Technology in Higher Education, Vol.14, no.1, pp. 4, 2017.

19. F. Cassano, A. Piccinno, T.Roselli, and V. Rossano.Gamification and learning analytics to improve engagement in university courses, in International Conference in Methodologies and Intelligent Systems for Technology Enhanced Learning,Springer, Cham, 2018, pp. 156-163. https://doi.org/10.1007/978-3-319-98872-6_19

20. A. P. Cavalcanti, A. Diego, R. F. Mello, K.Mangaroska, A. Nascimento, F.Freitas, and D. Gašević, et al.How good is my feedback? A content analysis of written feedback,in Proc. of the Tenth International Conference on Learning Analytics \& Knowledge, 2020, pp. 428-437. [Accepted] [In press].

21. R. Cerezo, M. Sánchez-Santillán, M. P.Paule-Ruiz, and J. C. Núñez.Students' LMS interaction patterns and their relationship with achievement: A case study in higher education, Computers \& Education, Vol. 96, pp. 42-54, 2016.

22. J. Chamizo-Gonzalez, E. I. Cano-Montero, E. UrquiaGrande, and C. I. Muñoz-Colomina, C. I. Educational data mining for improving learning outcomes in teaching accounting within higher education,The International Journal of Information and Learning Technology, Vol. 32, no. 5, pp. 272-285, 2015. https://doi.org/10.1108/IJILT-08-2015-0020

23. M.A. Chatti, A. L.Dyckhoff,U. Schroeder, and H. Thüs. A reference model for learning analytics,International Journal of Technology Enhanced Learning, Vol. 4, no. 5-6, pp. 318-331, 2013.

24. J. Chicaiza, M. C. Cabrera-Loayza, R. Elizalde, and N. Piedra.Application of data anonymization in Learning Analytics,in Proc. of the 3rd International Conference on Applications of Intelligent Systems, 2020, pp. 1-6.

25. A. Cobo, R. Rocha, and C. Rodríguez-Hoyos. Evaluation of the interactivity of students in virtual learning environments using a multicriteria approach and data mining,Behaviour \& Information Technology, Vol.33, no. 10, pp. 1000-1012, 2014.

26. A. Cohen, and U.Shimony (2016). Dropout prediction in a massive open online course using learning analytics,in E-Learn: World Conference on E-Learning in Corporate, Government, Healthcare, and Higher Education, AACE, 2016, pp. 616-625.

27. A. Cohen, U. Shimony, R.Nachmias, and T.Soffer. Active learners' characterization in MOOC forums and their generated knowledge,British Journal of Educational Technology, Vol. 50, no.1, pp. 177-198, 2019.

https://doi.org/10.1111/bjet.12670

28. L. Corrin, G. Kennedy, S. French, S. B. Shum, K.Kitto, A. Pardo, A., et al. The ethics of learning analytics in Australian higher education, 2019.

29. S. H. Cormack, L. A. Eagle, and M. S. Davies. A largescale test of the relationship between procrastination and performance using learning analytics, Assessment \& Evaluation in Higher Education,pp.1-14, 2020.

30. S. Dawson, S. Joksimovic, O.Poquet, and G. Siemens. Increasing the Impact of Learning Analytics, in Proc. of the 9th International Conference on Learning Analytics \& Knowledge, ACM, 2019, pp. 446-455.

31. J. Daz-Lzaro, I. S.Fernndez, and M.Snchez-Vera. Social Learning Analytics in Higher Education. An experience at the Primary Education stage,Journal of New Approaches in Educational Research (NAER Journal), Vol. 6, no. 2, pp. 119-126, 2017. https://doi.org/10.7821/naer.2017.7.232

32. M. S. DeBerard, G.Spielmans, and D.Julka. Predictors of academic achievement and retention among college freshmen: A longitudinal study,College student journal, Vol. 38, no. 1, pp. 66-80, 2004.

33. R. F. DeMara, T. Tian, and W. Howard. Engineering assessment strata: A layered approach to evaluation spanning Bloom's taxonomy of learning,Education and Information Technologies, Vol. 24, no. 2, pp. 1147 1171, 2019.

34. P. G. De Barba, D.Malekian, E. A. Oliveira, J. Bailey, T. Ryan, G. and Kennedy, et al.The importance and meaning of session behaviour in a MOOC, Computers \& Education, Vol. 146, pp.103772, 2020 .

35. I. Dimopoulos, O.Petropoulou, and S. Retalis.Assessing students' performance using the learning analytics enriched rubrics,in Proc. of the Third International Conference on Learning Analytics and Knowledge, ACM, 2013, pp. 195-199. https://doi.org/10.1145/2460296.2460335

36. B. Divjak, D. Grabar, and M.Maretic. Assessment Analytics for Peer-Assessment: A Model and Implementation,in PCLA@LAK, 2016, pp. 27-31.

37. H. Drachsler, and W. Greller.The pulse of learning analytics understandings and expectations from the stakeholders,in Proceedings of the 2nd international conference on learning analytics and knowledge, ACM, 2012, pp. 120-129.

38. B. Dragulescu, M.Bucos, and R. Vasiu. Predicting assignment submissions in a multi-class classification problem,TEM Journal, Vol. 4, no. 3, pp.244, 2015.

39. R. L. Dunbar, M. J.Dingel, and X. Prat-Resina. Connecting Analytics and Curriculum Design: Process and Outcomes of Building a Tool to Browse Data Relevant to Course Designers, Journal of Learning Analytics, Vol. 1, no. 3, pp. 223-243, 2014.

40. T. Elias.Learning analytics,Learning, pp. 1-22, 2011. 
41. M. Erkens, D. Bodemer, and H. U. Hoppe. Improving collaborative learning in the classroom: Text mining based grouping and representing,International Journal of Computer-Supported Collaborative Learning, Vol. 11, no. 4, pp. 387-415, 2016.

42. M. Ez-Zaouia, A. Tabard, and E.Lavoué. Emodash: A dashboard supporting retrospective awareness of emotions in online learning, International Journal of Human-Computer Studies, Vol. 139, pp. 102411, 2020. https://doi.org/10.1016/j.ijhcs.2020.102411

43. R. Ferguson.Learning analytics: drivers, developments and challenges, International Journal of Technology Enhanced Learning, Vol. 4, no. 5/6, pp. 304-317, 2012.

44. R. Ferguson, T. Hoel, M.Scheffel, and H.Drachsler.Guest editorial: Ethics and privacy in learning analytics, SoLAR, Vol. 3, no. 1, pp.5-15, 2016.

45. R. Ferguson. Learning Analytics: drivers, developments and challenges,Italian Journal of Educational Technology, Vol. 22, no. 3, pp.138-147, 2014.

46. R. Ferreira $\square$ Mello, M. André, A. Pinheiro, E., Costa, and C. Romero. Text mining in education, Wiley Interdisciplinary Reviews: Data Mining and Knowledge Discovery, Vol. 9, no. 6, pp. e1332, 2019.

47. B. Flanagan, and H. Ogata. Learning analytics platform in higher education in Japan,Knowledge Management \& E-Learning: An International Journal, Vol. 10, no. 4, pp. 469-484, 2018.

48. M. K. France, S. J. Finney, andP.Swerdzewski. Students' group and member attachment to their university: A construct validity study of the University Attachment Scale, Educational and Psychological Measurement, Vol. 70, no. 3, pp. 440458, 2010.

https://doi.org/10.1177/0013164409344510

49. Y. Gao, and G. S. Fu. Review of studies on learning analysis in education in China,China Med. Educ. Technol, Vol. 30, no. 1, pp. 23-26, 2016.

50. D. García-Saiz, and M.Zorrilla. E-learning web miner: A data mining application to help instructors involved in virtual courses,in Educational Data Mining, 2010.

51. O. B. Gene, M. M. Núñez, and A. F. Blanco.Gamification in MOOC: challenges, opportunities and proposals for advancing MOOC model, in Proc. of the Second International Conference on Technological Ecosystems for Enhancing Multiculturality, ACM, 2014, pp. 215-220.

52. A. Gibson, K. Kitto, and J. Willis.A cognitive processing framework for learning analytics, in Proc. of the fourth international conference on learning analytics and knowledge, ACM, 2014, pp. 212-216.

53. S. GOTTIPATI, and V. SHANKARARAMAN. Learning Analytics applied to curriculum analysis, in Proc. of the 2014 SIGED: IAIM Conference, Paper, 2014, Vol. 2.

54. S. Gottipati, V.Shankararaman, and J. R. Lin. Text analytics approach to extract course improvement suggestions from students' feedback,Research and Practice in Technology Enhanced Learning, Vol. 13, no. 1, pp.6, 2018.

55. J. Grann, and D.Bushway. Competency map: visualizing student learning to promote student success, in Proc. of the fourth international conference on learning analytics and knowledge, ACM, 2014, pp. 168-172.

https://doi.org/10.1145/2567574.2567622

56. W. Greller, and H.Drachsler. Translating learning into numbers: A generic framework for learning analytics,Educational Technology \& Society, Vol. 15, no. 3, pp.42-57, 2012.

57. A. Gruzd, and N. Conroy. Learning Analytics Dashboard for Teaching with Twitter, in Proc. of the 53rd Hawaii International Conference on System Sciences, 2020.

58. W. He. Examining students' online interaction in a live video streaming environment using data mining and text mining,Computers in Human Behavior, Vol. 29, no. 1, pp. 90-102, 2013.

59. J. Heath. Contemporary privacy theory contributions to learning analytics, Journal of Learning Analytics, Vol.1, no. 1, pp. 140-149, 2014.

60. M. Henderson, T. Ryan, and M. Phillips. The challenges of feedback in higher education,Assessment \& Evaluation in Higher Education, pp. 1-16, 2019.

61. C. Herodotou, B.Rienties, A.Boroowa, Z. Zdrahal, and M. Hlosta.A large-scale implementation of predictive learning analytics in higher education: the teachers' role and perspective,Educational Technology Research and Development, Vol. 67, no. 5, pp. 1273-1306, 2019. https://doi.org/10.1007/s11423-019-09685-0

62. I. Hilliger, C. Aguirre, C. Miranda, S. Celis, and M. Pérez-Sanagustín.Design of a curriculum analytics tool to support continuous improvement processes in higher education,in Proc. of the Tenth International Conference on Learning Analytics \& Knowledge, 2020, pp. 181-186[Accepted] [In press].

63. H. Hind, M. K.Idrissi, and S. Bennani. Applying text mining to predict learners' cognitive engagement, in Proc. of the Mediterranean Symposium on Smart City Application,ACM, 2017, p. 2.

64. M. P. Hrzenjak, M. Matetic, and M. B.Bakaric. Mining association rules in learning management systems, in 2015 38th International Convention on Information and Communication Technology, Electronics and Microelectronics (MIPRO), IEEE, 2015, pp. 986-991.

65. J. L. Hsu, H. W. Chou, and H. H. Chang. EduMiner: Using text mining for automatic formative assessment,Expert Systems with Applications, Vol. 38, no. 4, pp. 3431-3439, 2011.

66. Y. Hu, C. Donald, N.Giacaman, and Z. Zhu. Towards automated analysis of cognitive presence in MOOC discussions: a manual classification study, in Proc. of the Tenth International Conference on Learning Analytics \& Knowledge, 2020, pp. 135-140[Accepted] [In press]. 
67. N. Iam-On, and T.Boongoen. Generating descriptive model for student dropout: a review of clustering approach,Human-centric Computing and Information Sciences, Vol. 7, no. 1, p. 1, 2017. https://doi.org/10.1186/s13673-016-0083-0

68. M. A. A. Ismail, A.Ahmad, J. A. M. Mohammad, N. M. R. M.Fakri, M. Z. M. Nor, and M. N. M. Pa.Using Kahoot! as a formative assessment tool in medical education: a phenomenological study, BMC medical education, Vol. 19, no. 1, p. 230, 2019.

69. P. Jaaskela, V. Heilala, T.Karkkainen, and P. Hakkinen. Student agency analytics: learning analytics as a tool for analysing student agency in higher education, Behaviour \& Information Technology, pp. 1-19, 2020.

70. J. Jovanovic, D. Gasevic, C. Brooks, V. Devedzic, M.Hatala, T.Eap, Tand G. Richards. LOCO-Analyst: semantic web technologies in learning content usage analysis,International journal of continuing engineering education and life long learning, Vol. 18, no. 1, pp. 54-76, 2008.

71. J. Kasih, M.Ayub, and S. Susanto. Predicting students' final passing results using the Apriori algorithm, World Transactions on Engineering and Technology Education, Vol. 11, no. 4, pp. 517-520, 2013.

72. C. Kent, and A. Rechavi. Deconstructing online social learning: network analysis of the creation, consumption and organization types of interactions, International Journal of Research \& Method in Education, Vol. 43, no. 1, pp. 16-37, 2020.

73. E. A. Khousa, and Y. Atif. Social network analysis to influence career development,Journal of Ambient Intelligence and Humanized Computing, Vol. 9, no. 3, pp. 601-616, 2018.

https://doi.org/10.1007/s12652-017-0457-9

74. E. A. Khousa, Y. Atif, and M. M. Masud. (2015).A social learning analytics approach to cognitive apprenticeship,Smart Learning Environments, Vol. 2, no. 1 , p. 14

75. M. K. Khribi, M. Jemni, and O.Nasraoui. Automatic recommendations for e-learning personalization based on web usage mining techniques and information retrieval, in 2008 Eighth IEEE International Conference on Advanced Learning Technologies, IEEE,2008, pp. 241-245.

76. Y. H. Kim, and J. H. Ahn.A study on the application of big data to the korean college education system,Procedia Computer Science, Vol. 91, pp. 855861, 2016.

77. M. J. Kintu, C. Zhu, and E.Kagambe. Blended learning effectiveness: the relationship between student characteristics, design features and outcomes,International Journal of Educational Technology in Higher Education, Vol. 14, no. 1, p. 7, 2017.

78. S. Knight, S. Buckingham Shum, and K. Littleton.Epistemology, pedagogy, assessment and learning analytics, in Proc. of the Third International Conference on Learning Analytics and Knowledge, ACM, 2013, pp. 75-84.
79. E. Koh, A. Shibani, J. P. L. Tan, and H. Hong.A pedagogical framework for learning analytics in collaborative inquiry tasks: An example from a teamwork competency awareness program, in Proc. of the Sixth International Conference on Learning Analytics \& Knowledge, ACM, 2016, pp. 74-83.

80. V. Kovanovic, D.Gaševic, S. Dawson, S.Joksimovic, R. S. Baker, and M. Hatala. Penetrating the black box of time-on-task estimation, in Proc. of the Fifth International Conference on Learning Analytics \& Knowledge, ACM, 2015, pp. 184-193.

81. V. Kumar, and A. Chadha. Mining association rules in student's assessment data,International Journal of Computer Science Issues (IJCSI), Vol. 9, no. 5, p. 211, 2012.

82. C. Lawson, C. Beer, D. Rossi, T. Moore, and J. Fleming. Identification of 'at risk'students using learning analytics: the ethical dilemmas of intervention strategies in a higher education institution,Educational Technology Research and Development, Vol. 64, no. 5, pp. 957-968, 2016.

83. J. Lamsa, R. Hamalainen, P. Koskinen, J. Viiri, and J. Mannonen. The potential of temporal analysis: Combining log data and lag sequential analysis to investigate temporal differences between scaffolded and non-scaffolded group inquiry-based learning processes, Computers \& Education, Vol. 143, p. 103674, 2020.

84. P. Leitner, M. Ebner, and M. Ebner. Learning Analytics Challenges to Overcome in Higher Education Institutions, in Utilizing Learning Analytics to Support Study Success, Springer, 2019, pp. 91-104.

85. P. Leitner, M. Khalil, and M. Ebner. Learning analytics in higher education-a literature review, in Learning analytics: Fundaments, applications, and trends, Springer, 2017, pp. 1-23.

86. A. C. M. Leung. Gamification to Promote Challengebased Learning, 2020.http://dspace.cityu.edu.hk/handle/2031/9254.

87. L. Lim, S. Dawson, S.Joksimovic, and D. Gaševic. Exploring students' sensemaking of learning analytics dashboards: Does frame of reference make a difference?, in Proc. of the 9th International Conference on Learning Analytics \& Knowledge, ACM, 2019, pp. 250-259.

88. S. Lonn, S. J. Aguilar, and S. D. Teasley. Investigating student motivation in the context of a learning analytics intervention during a summer bridge program,Computers in Human Behavior, Vol. 47, pp. 90-97, 2015. https://doi.org/10.1016/j.chb.2014.07.013

89. E. Lotsari, V. S. Verykios, C.Panagiotakopoulos, and D.Kalles. A learning analytics methodology for student profiling, in Hellenic Conference on Artificial Intelligence, Springer, 2014, pp. 300-312.

90. S. Ma, G. L. Herman, J. H. Tomkin, J. P. Mestre, and M. West. Spreading Teaching Innovations in Social Networks: the Bridging Role of Mentors,Journal for STEM Education Research, Vol. 1, no. 1-2, pp. 60-84, 2018. 
91. L. P. Macfadyen, and S. Dawson. Numbers are not enough. Why e-learning analytics failed to inform an institutional strategic plan,Journal of Educational Technology \& Society, Vol. 15, no. 3, pp. 149-163, 2012.

92. L. P. Macfadyen, andP. Sorenson. Using LiMS (the learner interaction monitoring system) to track online learner engagement and evaluate course design, in Educational Data Mining 2010, 2010.

93. D. Malekian, J. Bailey, and G. Kennedy. Prediction of Students' Assessment Readiness in Online Learning Environments: The Sequence Matters, in Proc. of the Tenth International Conference on Learning Analytics \& Knowledge, 2020, pp. 382-391 [Accepted] [In press].

94. F. Martin, and A.Ndoye. Using learning analytics to assess student learning in online courses,Journal of University Teaching \& Learning Practice, Vol. 13, no. 3, p. 7, 2016.

95. G. Mendez, X. Ochoa, K. Chiluiza, and B. De Wever. Curricular design analysis: a data-driven perspective,Journal of Learning Analytics, Vol. 1, no. 3, pp. 84-119, 2014.

96. R. Mitra, and P. Chavan. DEBE feedback for large lecture classroom analytics, in Proc. of the 9th International Conference on Learning Analytics \& Knowledge, ACM, pp. 426-430.

97. C. Monroy, V. S. Rangel, and R. Whitaker. A strategy for incorporating learning analytics into the design and evaluation of a K-12 science curriculum,Journal of Learning Analytics, Vol. 1, no. 2, pp. 94-125. https://doi.org/10.18608/jla.2014.12.6

98. P. M. Moreno-Marcos, T. C. Pong, P. J. Muñoz-Merino, and C. D. Kloos. Analysis of the Factors Influencing Learners' Performance Prediction With Learning Analytics. IEEE Access, Vol. 8, pp. 5264-5282, 2020.

99. S. Nakamura, K. Nozaki, H. Nakayama, Y. Morimoto, and Y. Miyadera. Sequential Pattern Mining System for Analysis of Programming Learning History, in 2015 IEEE International Conference on Data Science and Data Intensive Systems, IEEE, 2015, pp. 69-74.

100.D. M. Naranjo, J. R. Prieto, G.Moltó, and A. Calatrava. A Visual Dashboard to Track Learning Analytics for Educational Cloud Computing, Sensors, Vol. 19, no. 13, p. 2952, 2019.

101.X. Ochoa, D. Suthers, K.Verbert, andE. Duval. Analysis and reflections on the third learning analytics and knowledge conference,Journal of Learning Analytics, Vol. 1, no. 2, pp. 5-22, 2014.

102.H. T. Ozturk, D.Deryakulu, H.Ozcinar, and D. Atal. Advancing learning analytics in online learning environments through the method of sequential analysis, in 2014 International Conference on Multimedia Computing and Systems (ICMCS), IEEE, 2014, pp. 512-516.

103.R. Paiva, I. I.Bittencourt, T.Tenório, P.Jaques, and S.Isotani. What do students do on-line? Modeling students' interactions to improve their learning experience, Computers in Human Behavior, Vol. 64, pp. 769-781, 2016.
104.C. Palazuelos, D. García-Saiz, and M.Zorrilla. Social network analysis and data mining: An application to the e-learning context, in International Conference on Computational Collective Intelligence, Springer, 2013, pp. 651-660.

105.Z.Papamitsiou, and A. A. Economides. Learning analytics and educational data mining in practice: $A$ systematic literature review of empirical evidence,Journal of Educational Technology \& Society, Vol. 17, no. 4, pp. 49-64, 2014.

106. A. Pardo, J. Jovanovic, JS. Dawson, D. Gaševic, and N. Mirriahi. Using learning analytics to scale the provision of personalised feedback,British Journal of Educational Technology, Vol. 50, no. 1, pp. 128-138, 2019. https://doi.org/10.1111/bjet.12592

107.A. Pardo, O.Poquet, R. Martínez-Maldonado, and S. Dawson. Provision of data-driven student feedback in la \& EDM,Handbook of Learning Analytics, pp.163174, 2017.

108.A. Pardo, and G. Siemens. Ethical and privacy principles for learning analytics,British Journal of Educational Technology, Vol. 45, no. 3, pp. 438-450, 2014.

109.Z. A. Pardos, Q. Y. Wang, and S. Trivedi. The Real World Significance of Performance Prediction,International Educational Data Mining Society, 2012.

110.P. A. Patil, and R. V. Mane. Prediction of Students Performance Using Frequent Pattern Tree, in 2014 International Conference on Computational Intelligence and Communication Networks, IEEE, 2014, pp. 10781082.

111.H. Paulheim, and R.Meusel. A decomposition of the outlier detection problem into a set of supervised learning problems,Machine Learning, Vol. 100, no. 23, pp. 509-531, 2015.

112.A. Peña-Ayala. Educational data mining: A survey and a data mining-based analysis of recent works, Expert systems with applications, Vol. 41, no. 4, pp. 1432-1462, 2014.

113.A. G. Picciano. The evolution of big data and learning analytics in American higher education,Journal of Asynchronous Learning Networks, Vol. 16, no. 3, pp. 9-20, 2012. https://doi.org/10.24059/olj.v16i3.267

114.L. K. Poon, S. C. Kong, M. Y. Wong, and T. S.Yau. Mining sequential patterns of students' access on learning management system, in International conference on data mining and big data, Springer, 2017, pp. 191-198.

115.A. Pradeep, S. Das, and J. J. Kizhekkethottam. Students dropout factor prediction using EDM techniques, in 2015 International Conference on Soft-Computing and Networks Security (ICSNS), IEEE, 2015, pp. 1-7.

116.N. Pratheesh, and T. Devi. Necessity of learning analytics in software engineering education,Journal of Engineering Science and Technology, Vol. 10, no. 3, pp. 269-281, 2015. 
117.P. Race. The lecturer's toolkit: a practical guide to assessment, learning and teaching,Routledge, 2019. https://doi.org/10.4324/9781315767277.

118.N. Rachburee, W. Punlumjeak, S. Rugtanom, D.Jaithavil, and M. Pracha. A prediction of engineering students performance from core engineering course using classification, in Information Science and Applications, Springer, 2015, pp. 649-656.

119.M. H. Rahman, and M. R. Islam. Predict Student's Academic Performance and Evaluate the Impact of Different Attributes on the Performance Using Data Mining Techniques, in 2017 2nd International Conference on Electrical \& Electronic Engineering (ICEEE), IEEE, 2017, pp. 1-4.

120.R. R.Rajalaxmi,P. Natesan,N. Krishnamoorthy, and S.Ponni. Regression Model for Predicting Engineering Students Academic Performance,International Journal of Recent Technology and Engineering (IJRTE), Vol. 7, pp. 71$75,2019$.

121.S.Ray, and M. Saeed. Applications of educational data mining and learning analytics tools in handling big data in higher education, in Applications of Big Data Analytics, Springer, 2018, pp. 135-160.

122.Z.Ren, H. Rangwala, and A. Johri. Predicting performance on MOOC assessments using multiregression models, arXiv preprint arXiv:1605.02269, 2016.

123.B. Rienties, A.Boroowa, S. Cross, L. Farrington-Flint, C.Herodotou, and L. Prescott et al. Reviewing three case-studies of learning analytics interventions at the open university UK, in Proc. of the Sixth International Conference on Learning Analytics \& Knowledge, ACM, 2016, pp. 534-535.

https://doi.org/10.1145/2883851.2883886

124.B. Rienties, and B. A. Rivers. Measuring and understanding learner emotions: Evidence and prospects,Learning Analytics Review, Vol. 1, pp. 1-28, 2014.

125.B. Rienties, and A. Jones. Using learning design and learning analytics to empower teachers to meet students' diverse needs, 2020 [In-press].

126.C. Romero, and S. Ventura. Data mining in education,Wiley Interdisciplinary Reviews: Data Mining and Knowledge Discovery, Vol. 3, no. 1, pp.1227, 2013.

127.M. Sailer, and L. Homner. The gamification of learning: a meta-analysis, 2019 . https://doi.org/10.1007/s10648-019-09498-w

128.D. J. Salas, S.Baldiris, R.Fabregat, and S. Graf. Supporting the Acquisition of Scientific Skills by the Use of Learning Analytics, in International Conference on Web-Based Learning, Springer, 2016, pp. 281-293.

129.M. Saqr, and A.Alamro. The role of social network analysis as a learning analytics tool in online problem based learning,BMC medical education, Vol. 19, no. 1, p. 160, 2019.

130.M. Saqr, U.Fors, and J. Nouri. Using social network analysis to understand onlineproblem-based learning and predict performance, $P l o S$ one, Vol. 13, no. 9, p. e0203590, 2018.

131.M. Saqr, J. Nouri, H.Vartiainen, and J.Malmberg. What makes an online problem-based group successful? A learning analytics study using social network analysis, BMC Medical Education, Vol. 20, no. 1, pp. 1-11, 2020.

132.H. E. Schaffer, K. R. Young, E. W.Ligon, and D. D. Chapman. Automating individualized formative feedback in large classes based on a directed concept graph,Frontiers in psychology, Vol. 8, p. 260, 2017.

133.M. Scheffel, K. Niemann, A. Pardo, D. Leony, M. Friedrich, K. Schmidt, et al. Usage pattern recognition in student activities, in European Conference on Technology Enhanced Learning, Springer, 2011, pp. 341-355.

134.C. Schumacher, and D.Ifenthaler. Features students really expect from learning analytics, Computers in Human Behavior, Vol.78, pp. 397-407, 2018.

135.C. Schumacher. Linking assessment and learning analytics to support learning processes in higher education, pp.1-40, 2020.

136.N. Sclater. Developing a Code of Practice for Learning Analytics,Journal of Learning Analytics, Vol. 3, no. 1, pp. 16-42, 2016.

137.N. Sclater, A.Peasgood, and J. Mullan. Learning analytics in higher education. A review of UK and international practice, $J I S C, 2016$.

138.A. Shoufan. Estimating the cognitive value of YouTube's educational videos: A learning analytics approach, Computers in Human Behavior, Vol. 92, pp. 450-458, 2019. https://doi.org/10.1016/j.chb.2018.03.036

139.S. B. Shum, and R. Ferguson. Social learning analytics,Journal of educational technology \& society, Vol. 15, no. 3, pp. 3-26, 2012.

140.G. Siemens. What are learning analytics, Retrieved February 10, $2016 \quad$ from http://www.elearnspace.org/blog/2010/08/25/what-arelearning-analytics/. 2010.

141.S. G. Siemens, and R. S. d Baker. Learning analytics and educational data mining: towards communication and collaboration, in Proc. of the 2 nd international conference on learning analytics and knowledge, ACM, 2012, pp. 252-254.

142.G. Siemens, D.Gasevic, C. Haythornthwaite, Dawson, S. B. Shum, R. Ferguson, et al. Open Learning Analytics: an integrated \& modularized platform, Doctoral dissertation, Open University Press, 2011.

143.G. Siemens, and P. Long. Penetrating the fog: Analytics in learning and education,EDUCAUSE review, Vol. 46, no. 5, p. 30, 2011.

144.S. Slade, and P. Prinsloo. Learning analytics: Ethical issues and dilemmas,American Behavioral Scientist, Vol. 57, no. 10, pp. 1510-1529, 2013.

145.D. Suganya,K. Kumar,P. S. Ramesh,and C.Suganthan.Student performance dashboard using mining approach, International Journal of Pure and Applied Mathematics, Vol. 119, pp. 409-418, 2018. 
146.S. Suganya,and V.Narayani.Higher Education System Using Data Mining Methods,Int. J. Adv. Res. Sci. Eng, Vol. 6, no. 3, p.8, 2017.

147.J. C. Y. Sun, C. T. Lin, and C. Chou. Applying learning analytics to explore the effects of motivation on online students' reading behavioral patterns,International Review of Research in Open and Distributed Learning, Vol.19, no. 2, 2018.

148.M. Sweeney, J. Lester, and H.Rangwala. Next-term student grade prediction, in 2015 IEEE International Conference on Big Data (Big Data), IEEE, 2015, pp. 970-975.

149.J. Swenson. Establishing an ethical literacy for learning analytics, in Proc. of the Fourth International Conference on Learning AnalyticsAnd Knowledge, ACM, 2014, pp. 246-250.

150.M. Tellakat, R. L. Boyd, andJ. W. Pennebaker. How do online learners study? The psychometrics of students' clicking patterns in online courses, $P$ loS one, Vol. 14, no. 3, p. e0213863, 2019.

151.D. Tempelaar. Supporting the less-adaptive student: the role of learning analytics, formative assessment and blended learning, Assessment \& Evaluation in Higher Education, 2019, DOI: $10.1080 / 02602938.2019 .1677855$.

152.D. Tempelaar, Q. Nguyen, and B.Rienties. Learning feedback based on dispositional learning analytics, in Machine Learning Paradigms, Springer, 2020, pp. 69-89.

https://doi.org/10.1007/978-3-030-13743-4_5

153.E. Tovar, and O. Soto. The use of competences assessment to predict theperformance of first year students, in 2010 IEEE Frontiers in Education Conference (FIE), IEEE, 2010, pp. F3J-1.

154.N. Tomasevic, N. Gvozdenovic, and S.Vranes. An overview and comparison of supervised data mining techniques for student exam performance prediction, Computers \& Education, Vol.143, p.103676, 2020.

155.C. Troussas, A.Krouska, and M.Virvou. Using a multi module model for learning analytics to predict learners' cognitive states and provide tailored learning pathways and assessment, in Machine Learning Paradigms, Springer, 2020, pp. 9-22.

156.Y. S. Tsai, D.Gasevic. Learning analytics in higher education---challenges and policies: a review of eight learning analytics policies, in Proc. of the seventh international learning analytics \& knowledge conference, ACM, 2017, pp. 233-242.

157.Y. S. Tsai, A. Whitelock-Wainwright, and D.Gašević. The privacy paradox and its implications for learning analytics, in Proc. of the Tenth International Conference on Learning Analytics \& Knowledge, 2020, pp. 230-239 [Accepted] [In press].

158.S. F. Tseng, Y. W. Tsao, L. C. Yu, C. L. Chan, and K. R. Lai. Who will pass? Analyzing learner behaviors in MOOCs, Research and practice in technology enhanced learning, Vol. 11, no. 1, p. 8, 2016.

159.A. van den Beemt, J. Buijs, and W. van der Aalst. Analysing structured learning behaviour in massive open online courses (MOOCs): an approach based on process mining and clustering,International Review of Research in Open and Distributed Learning, Vol. 19, no. 5, 2018.

160.J. M. Vytasek, A.Patzak, and P. H. Winne. Analytics for student engagement, in Machine Learning Paradigms, Springer, 2020, pp. 23-48.

161.X. Wang, D. Yang, M. Wen, K. Koedinger, and C. P. Rosé. Investigating How Student's Cognitive Behavior in MOOC Discussion Forums Affect Learning Gains, International Educational Data Mining Society, 2015.

162.Y. Wang. Big opportunities and big concerns of big data in education,TechTrends, Vol. 60, no. 4, pp. 381384, 2016.

163.K. Welbers, E. A.Konijn, C. Burgers, A. B. de Vaate, A. Eden, B. C.Brugman. Gamification as a tool for engaging student learning: A field experiment with a gamified app,E-Learning and Digital Media, Vol. 16, no. 2, pp. 92-109, 2019,

164.A. F. Wise, D. W. Shaffer. Why theory matters more than ever in the age of big data,Journal of Learning Analytics, Vol. 2, no. 2, pp.5-13, 2015.

165.A. Wolff, Z.Zdrahal, A.Nikolov, M.Pantucek(2013). Improving retention: predicting at-risk students by analysing clicking behaviour in a virtual learning environment, in Proc. of the third international conference on learning analytics and knowledge, ACM, pp. 145-149.

166.J. Wong, M. Khalil, M. Baars, B. B. de Koning, and F.Paas. Exploring sequences of learner activities in relation to self-regulated learning in a massive open online course,Computers \& Education, p. 103595, 2019.

https://doi.org/10.1016/j.compedu.2019.103595

167.W. Y. Wong, and M.Lavrencic. Using a Risk Management Approach in Analytics for Curriculum and Program Quality Improvement, in PCLA@ $L A K$, 2016, pp. 10-14.

168.W. Xing, R. Guo, E.Petakovic, S.Goggins. Participation-based student final performance prediction model through interpretable Genetic Programming: Integrating learning analytics, educational data mining and theory,Computers in Human Behavior, Vol. 47, pp. 168-181.

169.W. Xing, B. Wadholm, and S.Goggins. Learning analytics in CSCL with a focus on assessment: an exploratory study of activity theory-informed cluster analysis, in Proc. of the fourth international conference on learning analytics and knowledge, ACM,2014, pp. 59-67.

170.Y. Xiong,and H. K. Suen. Assessment approaches in massive open online courses: Possibilities, challenges and future directions, International Review of Education, Vol. 64, no. 2, pp. 241-263, 2018.

171.S. Yassine, S. Kadry, and M. A. Sicilia. A framework for learning analytics in moodle for assessing course outcomes, in 2016 IEEE Global Engineering Education Conference (EDUCON), IEEE,2016, pp. 261-266. 
172.Y. Yoo, H. Lee, I. H. Jo, and Y. Park. Educational dashboards for smart learning: Review of case studies, in Emerging issues in smart learning, Springer, 2015, pp. 145-155.

173.J. W. You. Identifying significant indicators using LMS data to predict course achievement in online learning,The Internet and Higher Education, Vol. 29, pp. 23-30, 2016.

174.S. H. Zheng, and X. Q. Xi. Theoretical Research on Early Warning Analysis of Students' Grades, in The Euro-China Conference on Intelligent Data Analysis and Applications, Springer, 2019, pp. 441-449.

175.J. Zheng, W. Xing, G. Zhu, G. Chen, H. Zhao, and C.Xie et al. Profiling self-regulation behaviors in STEM learning of engineering design, Computers \& Education, Vol. 143, p. 103669, 2020.

176. G. Zhu, W. Xing, and V. Popov. Uncovering the sequential patterns in transformative and nontransformative discourse during collaborative inquiry learning, The Internet and Higher Education, Vol. 41, pp. 51-61, 2019.

177.https://www.reportlinker.com/p05839708/?utm_source= GNW.

178.O. Dahiya and K. Solanki, S. Dalal, A. Dhankhar, Regression Testing: Analysis of its Techniques for Test Effectiveness,International Journal of advanced trends in computer science and engineering, Vol. 9, No. 1, pp. 737-744, 2020.

179. O. Dahiya and K. Solanki, Comprehensive cognizance of Regression Test Case Prioritization Techniques, International journal of emerging trends in engineering research, Vol. 7 No. 11, pp. 638-646, 2019. https://doi.org/10.30534/ijeter/2019/377112019

180.O. Dahiya and K. Solanki, S. Dalal, A. Dhankhar, An Exploratory Retrospective Assessment on the Usage of Bio-Inspired Computing Algorithms for Optimization, International journal of emerging trends in engineering research, Vol. 8 No. 2, pp. 414-434, 2020 . https://doi.org/10.30534/ijeter/2020/29822020

181.O. Dahiya and K. Solanki, and A. Dhankhar, RiskBased Testing: Identifying, Assessing, Mitigating \& Managing Risks Efficiently In Software Testing, International Journal of advanced research in engineering and technology, Vol. 11, Issue 3, pp. 192203, 2020.

182.K. Solanki, and S. Kumari, Comparative study of software clone detection techniques, In 2016 Management and Innovation Technology International Conference (MITicon), pp. MIT-152, IEEE, 2016

183.O. Dahiya, and K. Solanki, A systematic literature study of regression test case prioritization approaches, International Journal of Engineering \& Technology, 7(4), pp.2184-2191, 2018.

184.K. Solanki, Y. Singh, and S. Dalal, Experimental analysis of $\mathrm{m}$-ACO technique for regression testing, Indian Journal of Science and Technology, 9(30), pp.1-7.

185.O. Dahiya, K. Solanki and S. dalal, Comparative Analysis of Regression Test Case Prioritization Techniques,International Journal of advanced trends in computer science and engineering, Vol. 8 No. 4, pp. 1521-1531, 2019. https://doi.org/10.30534/ijatcse/2019/74842019

186.A. Dhankhar and K. Solanki, State of the Art of Learning Analytics in Higher Education, International journal of emerging trends in engineering research, Vol. 8 No. 3, pp. 868-877, 2020. https://doi.org/10.30534/ijeter/2020/43832020

187.A. Dhankhar and K. Solanki, A Comprehensive Review of Tools \& Techniques for Big Data Analytics, International journal of emerging trends in engineering research, Vol. 7 No. 11, pp. 556-562, 2019. https://doi.org/10.30534/ijeter/2019/257112019

188.M. Hooda, and C. Rana. Learning Analytics: Transforming Higher Education and Learning Excellences, International Journal of Advanced Science and Technology, Vol. 29, no. 9, pp. 218-230, 2020. 